\title{
The geography of smoking in Leeds: estimating individual smoking rates and the implications for the location of stop smoking services
}

\author{
Melanie N Tomintz*, Graham P Clarke* and Janette E Rigby** \\ *School of Geography, University of Leeds, Leeds LS2 9JT \\ Email: m.tomintz05@leeds.ac.uk \\ **Department of Geography, University of Sheffield, Sheffield S10 2TN
}

Revised manuscript received 29 April 2008

\begin{abstract}
Smoking is an important and topical health issue in the UK. In Leeds, the target is to reduce smoking prevalence by 9 per cent by 2010. However, a key unknown is the likely distribution of smokers across the city. This paper aims to estimate individual smoking rates using microsimulation and hence evaluate the performance of established stop smoking services, e.g. how well do they serve local areas and to what extent does attendance vary between service point locations? Location-allocation modelling is employed to test various location scenarios and provide insight into where to optimally place centres.
\end{abstract}

Key words: health geography, microsimulation, geography of smoking, location-allocation modelling, stop smoking services

\section{Introduction}

To cease smoking is the easiest thing I ever did. I ought to know because I've done it a thousand times. (Mark Twain)

Smoking is the largest cause of preventable death in Britain and is responsible for various types of cancer (notably lung cancer) and heart disease. Peto (1994) points out that 30 per cent of all deaths for people aged 35 to 69 in Britain are due to smoking and nowadays this habit is responsible for around 86500 deaths a year (Department of Health 2006). A related health issue is that of passive smoking, where people are at greater risk of developing lung cancer and coronary heart disease when living with a person who smokes (Hackshaw et al. 1997; He et al. 1999). Children in households that have a smoker are often exposed to health risks, but a study by Blackburn et al. (2003) showed that only 20 per cent of parents stop smoking in the home to protect their children. The consequences are that such children can have higher incidences of lower respiratory tract infections, greater absenteeism from school and higher use of health services (Stanton et al. 2005).

Smoking is an important factor driving geographical variations in mortality, but most studies focus on national or regional trends and less has been done at the small area level (Pearce et al. 2003). The national target in England is to reduce the number of smokers by 2010 from 26 per cent down to 21 per cent (Department of Health 2004). To help smokers quit, stop smoking services were set up in 1999, raising a crucial geographical question: 'where should these facilities be located?' The recent White Paper Our health, our care, our say: a new direction for community services (Department of Health 2006) highlights the increasing need to provide more services away from hospitals and clinics and into community areas (particularly hard-to-reach communities 
that might contain large numbers of poor residents or ethnic minority groups). This is a particularly important policy as statistics show that smoking rates are much higher in population groups of low socio-economic status (Goddard 2006). Thus, when attempting to reduce health inequalities, it is important that efforts are concentrated in more deprived communities.

Statistics also show that smoking rates vary by age, socio-economic status and ethnicity. The smoking rate in the UK has decreased steadily over time, especially for men. In the 1970 s, more than 50 per cent of the male and 40 per cent of the female population smoked, whereas by 2006 the rate has declined to 27 per cent for men and 21 per cent for women (Goddard 2006). Smoking rates vary amongst different age groups, with people aged 20-24 the most likely to smoke. A high number of young people are seduced into smoking at an early age (often through peer pressure) and Stanton et al. (2005) and Sargent and Dalton (2001) report that children who start smoking at an early age are more likely to smoke into adulthood (Department of Health 1998).

An important issue for understanding spatial variations in smoking within a city or region is the strong association between smoking and socioeconomic class. In general the proportion of smokers in higher socio-economic classes (such as people in managerial and professional occupations) is less than in lower socio-economic classes. People in lower income groups often smoke to cope with stress (Datta et al. 2006) and in turn, tend to have higher stress levels (Elliott 2000). Further, Barbeau et al. (2005) discovered that in the US the number of tobacco advertisements in lower socio-economic communities is higher in comparison with those in higher income communities, and the focus of tobacco companies is mainly on minority communities with low incomes (Luke et al. 2000). Other indicators related to socio-economic status, such as unemployment, housing tenure and car availability, are also good predictors for smoking prevalence and health inequalities in general (Gordon et al. 1999).

Smoking prevalence also varies between and within different ethnic groups. The highest smoking rate in the UK can be found for Bangladeshi men (around $45 \%$ ), whereas Indian women record rates as low as 4 per cent. The highest prevalence amongst women is found for White and Asian women, with around 33 per cent, whilst the lowest smoking rates for men come from the Indian community, with 17 per cent. Looking at all persons, the lowest rates are found for the Indian population, with 10 per cent, and the highest rates for the White and Black African community, with 33 per cent (Goddard 2005).

Geodemographic variations in the resident population are likely to cause significant variations in small-area smoking rates. However, there are few detailed statistics that identify rates of smoking at small geographical areas, making policy implementation challenging. Estimates of small-area rates have been produced by Twigg and colleagues, who used multi-level synthetic estimations at ward level (Twigg et al. 2000 2004). Further research on small-area estimates of smokers can be found in Pearce et al. (2003) and Vaish et al. (2004). These authors focused on one or two variables, such as sex and age. An advantage of the microsimulation method used in this paper is that it can consider a larger number of variables.

The aim of this paper is to provide a clearer understanding of the geographical variations in smoking rates and to suggest an approach for locating more stop smoking services within areas of high need. This maps well on to increasing interest between health inequalities and social exclusion in UK cities in particular (Department of Health 2006). The study area selected is Leeds, West Yorkshire, UK which consists of approximately 750000 people.

The rest of the paper is structured as follows: first the current policy situations both in the UK and Leeds are highlighted and future plans to reduce the smoking population in the city are outlined. Attention is also given to the issue of passive smoking. Second, the paper explores the inequalities in smoking patterns, focusing on estimates of smoking prevalence by age, socio-economic status and ethnicity. As each of these attributes shows different spatial patterns of smoking, a microsimulation approach is used to combine those attributes to produce more robust estimates of smoking rates. Third, the performance of existing stop smoking centres is evaluated in terms of market penetration (how well they serve the estimated smokers). Fourth, the methodology of location-allocation modelling is used to demonstrate different scenarios illustrating possible locations of stop smoking services in Leeds. This enables policymakers to make comparisons between current and optimal locations and identify good locations for new centres. Finally, it is argued that such a novel combination of microsimulation and location-allocation models will offer health planners considerable power to examine 'what if' scenarios of future smoking patterns. 


\section{Smoking and smoking cessation services}

Concern over the links between smoking and illhealth has developed since the pioneering work of Doll and Hill (1950), although these concerns took considerable time to be translated into policy (Edwards 2004). The first successful steps against smoking in the UK were taken in the 1960 s by banning the advertising of cigarettes on television. However, in comparison with other countries such as Norway, France and Australia, the UK was weaker in developing anti-smoking policies despite the Department of Health's (1992) review on advertising smoking. In 1998, the Department of Health published a White Paper entitled Smoking kills: a white paper on tobacco, which argued that National Health Service (NHS) services were needed to help smokers who wanted to quit. The main groups targeted are (Department of Health 1998 2004):

- Adults (in general), with the aim of reducing smoking rates from 28 per cent to 26 per cent by 2005 and 21 per cent by 2010 .

- People aged below 16, with the aim of reducing prevalence of their smoking from 13 per cent in 1998 to 11 per cent by 2005 and 9 per cent by 2010.

- Adults in different social classes, with the focus on the manual group as it has the highest smoking prevalence. Here the aim is to reduce the smoking rate from 31 per cent in 2002 to 26 per cent or less by 2010 .

- Women who smoke during pregnancy, where the aim is reduce the smoking prevalence from 23 per cent in 1998 to 18 per cent in 2005 and 15 per cent or less by 2010 .

In Leeds, around 30 per cent of the adult population smokes. To meet the UK national targets, Leeds needs to reduce this to 21 per cent, which represents about 55000 adult smokers (The Healthy Leeds Partnership 2006). This is a huge challenge, as it means that almost one in three smokers will have to quit. A recent White Paper in 2004, Choosing health: making healthy choices easier, consisted of plans to make public areas, such as offices and factories, smoke free (Department of Health 2004). England and Wales became smoke free in all public areas on 1 July 2007 to protect against passive smoking and to continue to reduce smoking prevalence. Fichtenberg and Glantz (2002) show that restrictions on smoking in workplaces do encourage smokers to stop smoking or at least to reduce their cigarette consumption.

It is estimated that 70 per cent of people would like to stop smoking but perceive it to be very difficult (Department of Health 2004). The NHS has recognised this problem and has invested extensively in stop smoking services. These services are free of charge, and people can self-refer or can be referred by health professionals. Services consist of either one-to-one or group sessions with a trained advisor. In addition, free telephone help lines, an information website and nicotine replacement therapies have been introduced.

\section{Estimating small-area smoking rates}

In the Introduction it was shown that smoking rates vary depending on different geodemographic variables. Here, the variables age and socio-economic class are mapped for Output Areas (OAs) in Leeds using data from the General Household Survey (GHS) of 2006 (Goddard 2006) and the UK Census 2001 (Figures 1 and 2). Figure 1 shows the estimated smallarea smoking rates based on the individual age of residents in Leeds OAs and the national smoking rates by age group available from the GHS. For instance, it is known that the national smoking rate for people aged 20-24 is 31 per cent. Thus, if there are 16 people aged $20-24$ living in a Leeds OA, then we can multiply the national smoking rate $(31 \%)$ by the number of people (16) to generate the number of smokers for this age group. This is then applied to all age groups (as smoking rates vary for different age groups) to obtain the total number of smokers in each of the 2439 OAs in Leeds. The same procedure was carried out to estimate small-area smoking rates by socio-economic class. This, however, produces a very different picture of smoking rates (Figure 2). We have also estimated smoking rates by ethnicity (not shown here) and, again, the spatial patterns are different.

Figures 1 and 2 demonstrate variations in smoking prevalence by age and socio-economic class. Ideally, therefore, we need to estimate smoking prevalence by sex, age, socio-economic class and ethnicity (which are the main predictors of smoking) simultaneously. To do this we employ a microsimulation technique where it is possible to combine all relevant variables with the advantage of obtaining one result of smoking estimates. Large-scale datasets based on the attributes of individuals are built and 'what if' analyses are powerful to model the impacts of 


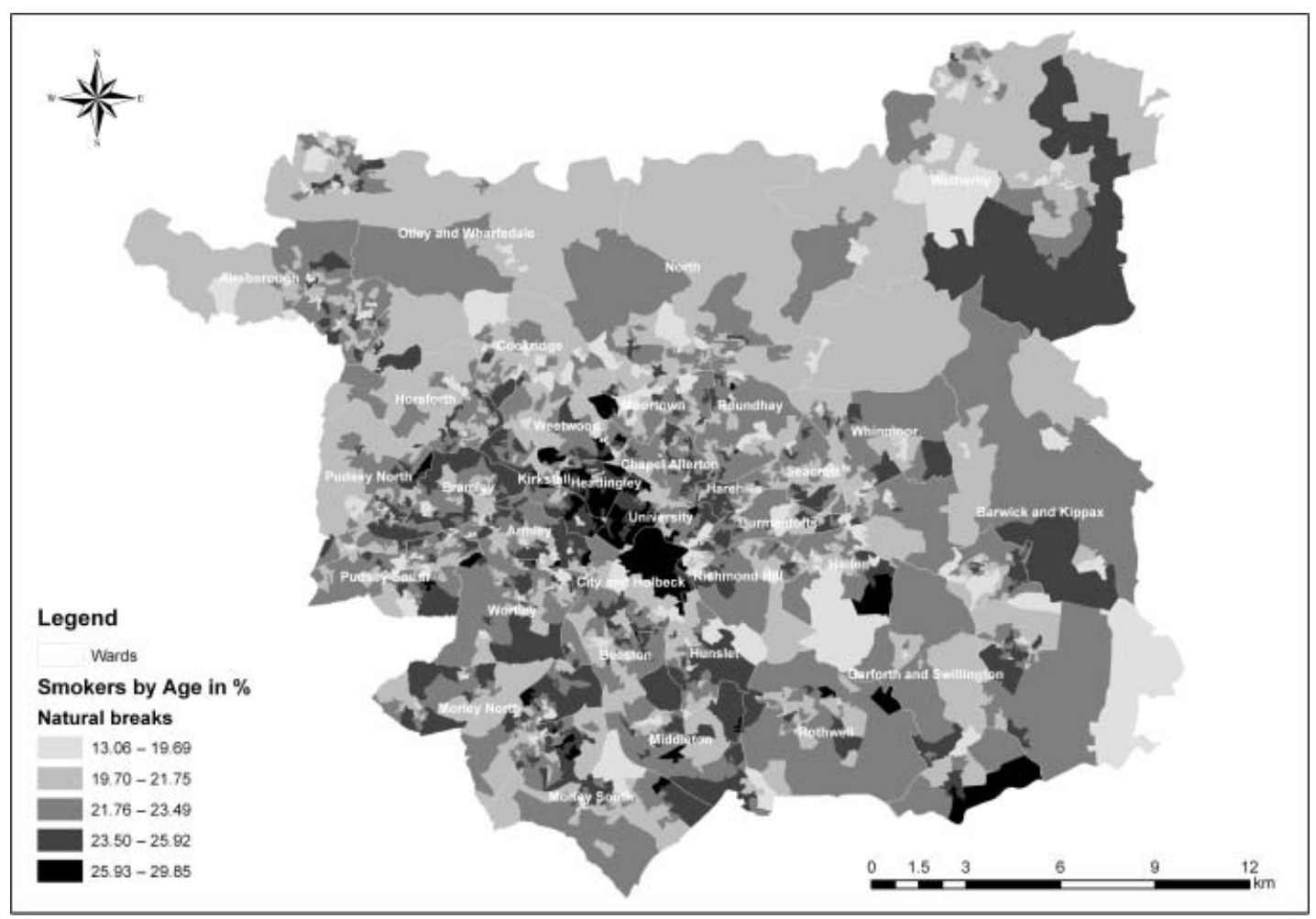

Figure 1 Smoking rates estimated using age for Leeds Output Areas (2006)

changing household demographics. Such microsimulation models cover many policy-relevant issues in welfare geography and are used to analyse policy impacts based on microunits (Birkin and Clarke 1995; Clarke 1996; Orcutt et al. 1986).

In this paper, the microsimulation method applies a static deterministic reweighting approach developed at the University of Leeds (Smith et al. in press). In the model two data sets are used: the General Household Survey (GHS) $2005(\mathrm{n}=19480)$ and the UK Census 2001. The GHS is an annual crosssectional survey that holds information on individuals and households at the regional level and the survey consists of more than 1000 variables including information about a person's lifestyle, such as smoking and drinking. The UK Census is conducted every ten years and the most recent data available are for 2001. The Census provides a rich dataset on demographic and socio-economic information, including age and socio-economic class, for the whole population down to OAs (where one OA consists of around 250 people), although no information about smoking is given.
The microsimulation model consists of four constraint variables (which have to be available in both data sets), namely sex, age, socio-economic class and ethnicity. These variables are grouped and entered sequentially into the model as socioeconomic class (five categories), age (six categories), ethnicity (five categories) and sex (two categories). The order of constraints is important as the first variable is reproduced most accurately. The deterministic microsimulation modelling used here is a kind of 'cloning' exercise where individuals from the GHS are selected to populate each OA if they match the socio-economic conditions used as constraints. Further, marital status (two categories) is used as an unconstrained or validation variable as it is also a predictor if someone is a smoker or not (but the variables mentioned before are stronger). An error threshold is set where the simulated constraint variables are compared with the actual constraint variables where the error is less than 10 per cent for 90 per cent of the OAs. For the validation variable marital status, the threshold is set to less than 20 per cent of error in 90 per cent of the OAs 


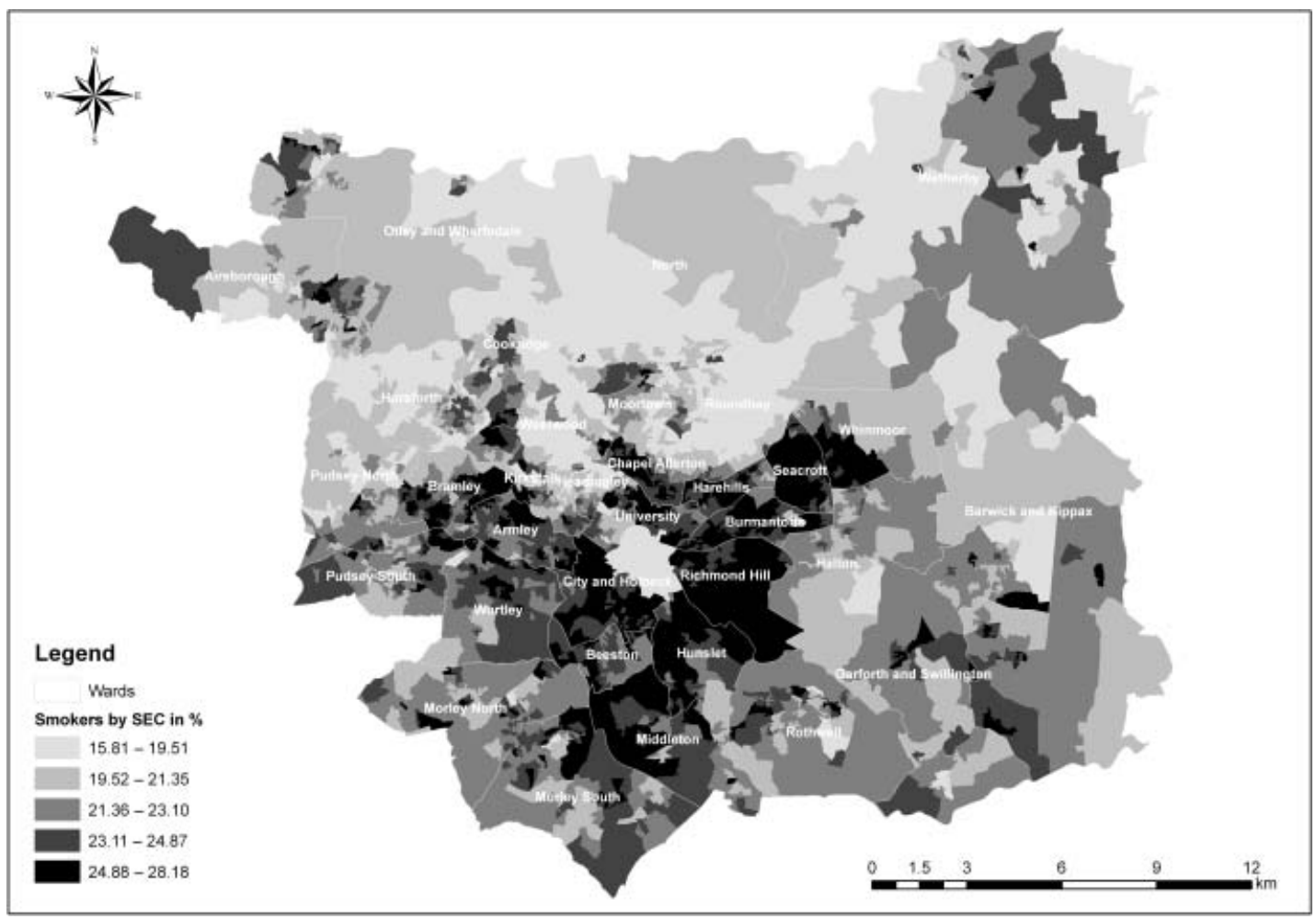

Figure 2 Smoking rates estimated using socio-economic group for Leeds Output Areas (2006)

as the validation variables are more difficult to model. The criteria were successfully met in this application. More detail of the microsimulation methodology appears elsewhere (Ballas et al. 2005; Clarke 1996; Smith et al. in press).

Figure 3 shows the estimates of smoking from the microsimulation (based on a combination of age, sex, socio-economic class and ethnicity). This map of smoking rates clearly picks out areas of Leeds where smoking is driven by age (student areas such as Headingley and University), social class (most of East and South Leeds) and ethnicity (low rates in some inner city areas driven by low smoking rates of Asian women). Although it is recognised that the smoking rates in Figure 3 are still only estimates, we argue that these are a substantial improvement on rates estimated using only one variable.

\section{Market penetration analysis of stop smoking services}

Having estimated small-area smoking prevalence rates, the next task is to evaluate the performance of existing stop smoking centres. Data supplied by the Leeds Primary Care Trust (PCT) showed that in October 2006 there were 51 service points in Leeds, with considerable variation in days and times of opening. For example, on a typical Monday, 11 centres were available, whereas on a Saturday there were only two centres open. Most of the facilities are located close to the city centre. There are no centres in the north at all and only two locations cover the whole north-east and eastern parts of Leeds. Planning stop smoking services is a complex task because the PCT is quite flexible as to where to set up its services and hence numerous options are available (providing suitable premises can be found). It can respond to complaints by setting up services where there are a large number of new requests for help. Hence ongoing changes can be made but in a rather haphazard way. Obviously stop smoking services will have greater success when focusing on people who wish to stop. According to The Healthy Leeds Partnership (2006), there is $£ 2.1$ million available over the next three years for smoking cessation services. Further specialised services are 


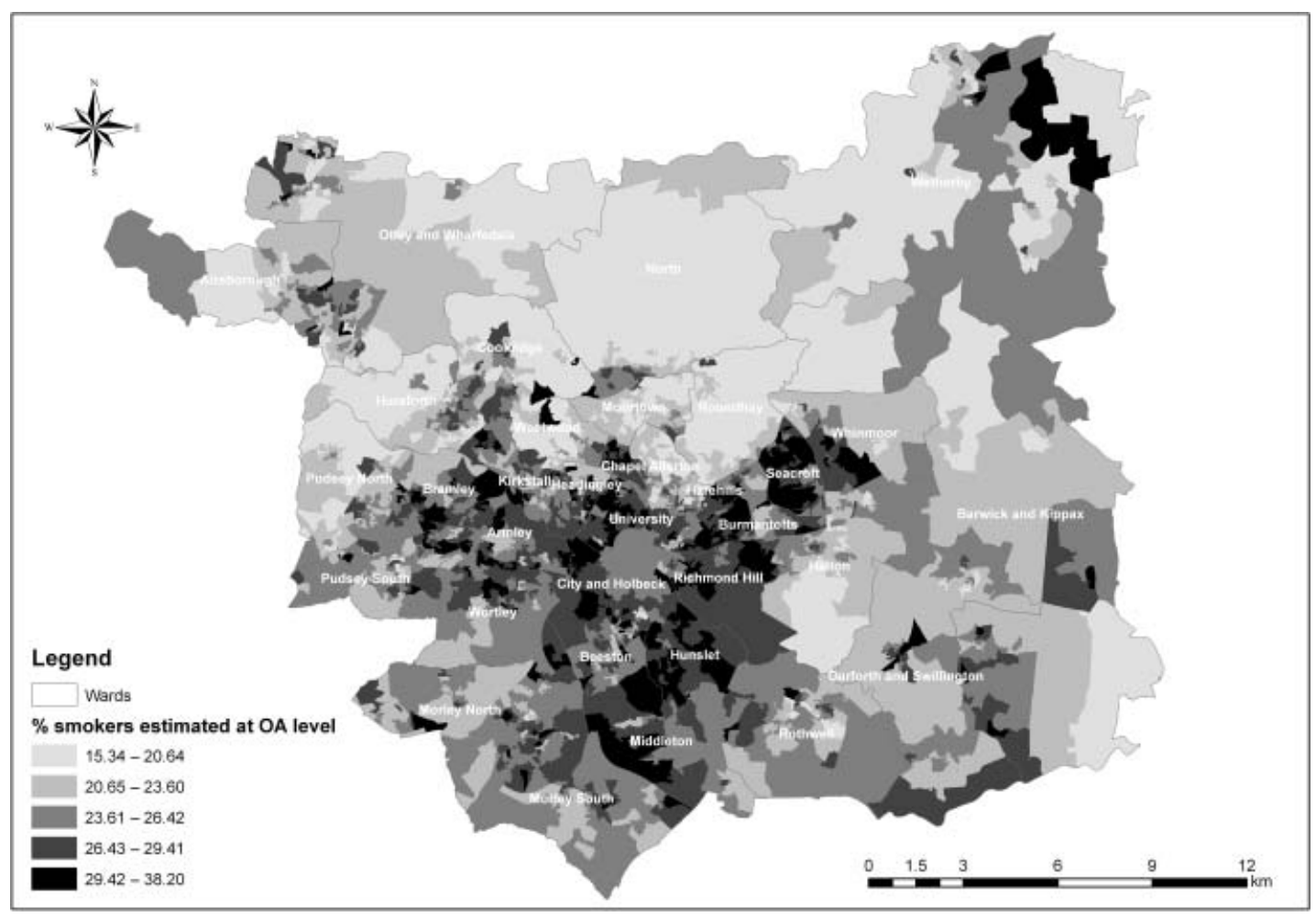

Figure 3 Estimated smoking rates for Leeds Output Areas from the spatial microsimulation

Table 1 Example of data set obtained from the Leeds PCT

\begin{tabular}{|l|l|l|l|l|l|l|l|l|l|l|l|}
\hline 1 & Sex & Age & Ethnicity & Postcode & Clinic Date & Clinic Room & Time & Att? & *4 week outcome & $* 52$ week outcome & ID No \\
\hline 2 & 2 & 16 & & $29 / 06 / 2006$ & Stop Smoking Service 1 & $12 \mathrm{pm}$ & No & No quit date set & No quit date set \\
\hline 3 & 1 & & & $29 / 06 / 2006$ & Stop Smoking Service 1 & $12 \mathrm{pm}$ & No & Quit \\
\hline 4 & 1 & 42 & & $29 / 06 / 2006$ & Stop Smoking Service 1 & $12 \mathrm{pm}$ & No & No quit date set & No quit date set \\
\hline 5 & 2 & 72 & & $29 / 06 / 2006$ & Stop Smoking Service 2 & $12 \mathrm{pm}$ & No & Quit & Relapsed \\
\hline 6 & 1 & 74 & White & $08 / 03 / 2006$ & Stop Smoking Service 2 & $5: 30 \mathrm{pm}$ & Yes & Lost \\
\hline 7 & 1 & 37 & White & $26 / 04 / 2006$ & Stop Smoking Service 3 & $5.30 \mathrm{pm}$ & Yes & Lost \\
\hline 8 & 2 & 35 & White & $08 / 03 / 2006$ & Stop Smoking Service 3 & $5: 30 \mathrm{pm}$ & Yes & Quit & Lost \\
\hline
\end{tabular}

also available, such as services for South Asian Communities ('Tambakoo') or services for pregnant women ('Fresh Air Babies') to encourage visits to stop smoking services.

Analysing areas where a high number of smokers attend any of the services is important for planning, as it is then possible to see what kind of population groups are most likely to give up and make use of a stop smoking session. Further research can then explore why people from these areas attend any particular service. For example, better media campaigns in certain areas achieve a higher attendance at certain centres. For the analysis in this paper, data on persons who contacted one of the smoking cessation services in Leeds between October 2004 and September 2006 were obtained from the Leeds PCT at the unit postcode level. The dataset contains information on 4068 people (of whom 2394 attended a session and 1674 did not) including sex, age, ethnicity and unit postcode address. Data are available on persons actually attending a service, which centre they attended and at what time, and if they stopped smoking after 4 weeks and 52 weeks. Table 1 shows a sample of the data. 


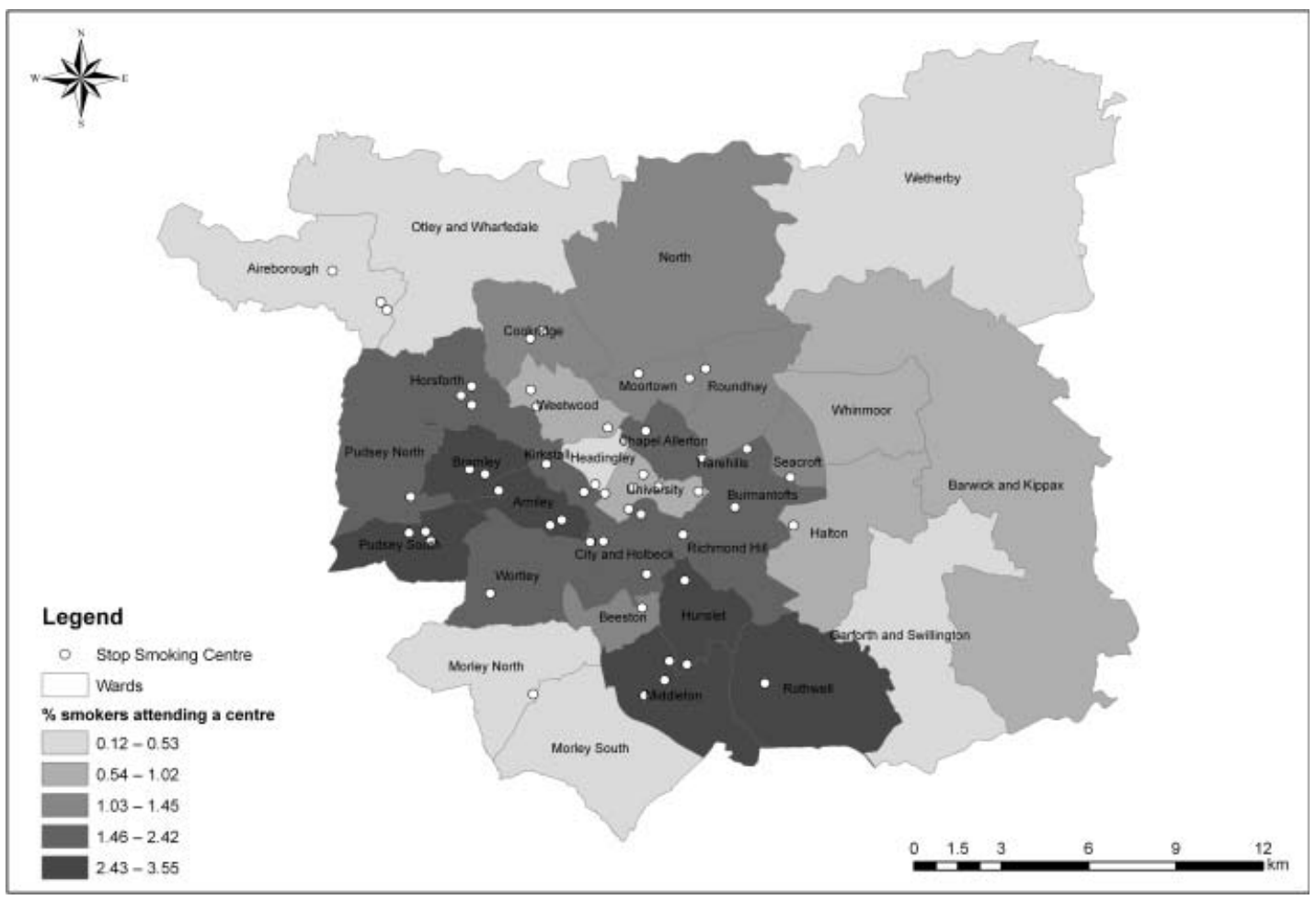

Figure 4 Market penetration of stop smoking centres in Leeds by ward

As shown above in Figure 3, our demand estimations of smokers according to sex, age, socio-economic class and ethnicity are made at Census OA level but the stop smoking centre dataset holds information at unit postcode level. Therefore it was necessary to match the data by using look up tables to see which postcode belongs to which Census OA. This information can be downloaded from UKBORDERS (http://borders.edina.ac.uk/html/lut_download/eng_ pctooa.html; accessed 27 February 2007). Having information on the number of attendees for each stop smoking centre along with the OA estimations of numbers of smokers means it is possible to analyse the market share or penetration of the different centres by calculating the proportion of smokers attending a centre. As the OA level is a very fine level of spatial resolution, the data are aggregated to ward level to get a broader picture of how effective centres are. Figure 4 shows that the highest market penetration is found in the south (Rothwell, Middleton and Hunslet) and the west (Pudsey South, Bramley and Armley) and the lowest market penetration in the centre of Leeds (Headingley) and the north-east (Garforth and Swillington).
A corresponding analysis can be completed for people who contacted any of the stop smoking services but did not actually attend $(\mathrm{n}=1674)$ (Figure 5). It can be seen that Beeston, Middleton and Hunslet in the South and Burmantofts in the centre of Leeds have the highest number of people who contacted a service but did not show up. However, three stop smoking services are located in Middleton, two in Hunslet, one in Beeston and one in Burmantofts, so people should be aware of these services nearby. The actual reason for not turning up is not known and in-depth research is needed to understand this. Reasons could include the opening hours or the day the service operates. Barriers such as language problems for immigrant populations could be another possible reason. Interestingly, in terms of future provision, it was found that most people attended sessions from 6 pm onwards, which shows the importance of timing sessions outside main working hours. Also of interest are that women were more likely to attend a stop smoking session than men and that people in the age group 30-44 were most likely to attend any of the services. 


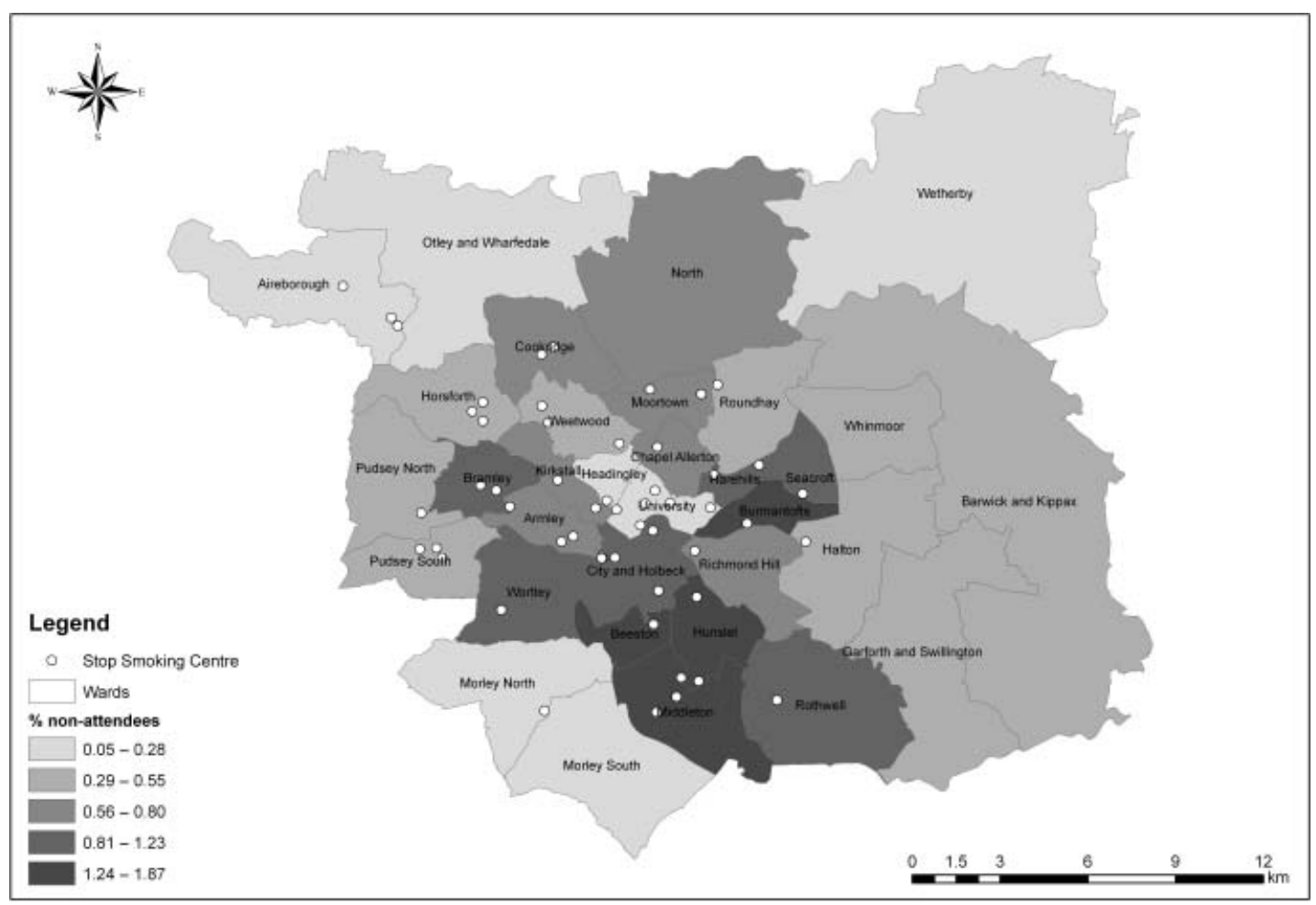

Figure 5 Proportion of estimated smokers who booked an appointment and failed to attend

Analysing individual centres gives useful information on different catchment area sizes. Figure 6 shows the results for Seacroft Hospital in East Leeds. The map shows a wide catchment area for the centre, highlighting that Seacroft Hospital is one of the centres with the highest attendance records. Figure 6 highlights high attendance in relation to smokers in Seacroft itself (where the centre is located) and in Richmond Hill and Burmantofts, which are adjacent wards. High attendance can also be seen from the north-east and eastern part of Leeds, where no centre was located at the time of the analysis. Such market analysis can help health planners target areas where current penetration of the smoking community is low.

\section{Optimally locating stop smoking services}

Location-allocation models are a tried and tested modelling technique for locating facilities in the best possible way given the location of demand. With such models it is possible to understand complex relationships between access and facility location and variations over space and time (Nemet and Bailey 2000). Most models assume a person will be allocated to his/her nearest facility, so the objective is then to minimise total travel cost or distance for all persons. The most common location model is called the p-median model and was first defined by Hakimi (1964), where a set of constraints are defined and each demand site (here the number of smokers at OA level) is allocated to only one facility (stop smoking centre) so that all service needs are met. If the interest lies in locating facilities to cover a set of demand sites within a defined travel distance or time, then the location set covering problem (LSCP) is the most appropriate (Toregas et al. 1971). The maximal covering problem (MCP) uses elements of the p-median problem and the LSCP to locate a number of facilities within a set of supply sites (Church and ReVelle 1974). This should maximise the number of people obtaining a certain service and it is mainly used for emergency service facilities. For more information on location-allocation and healthcare planning see Hodgson (1988), Ross et al. (1994) and Møller-Jensen and Kofie (2001). 


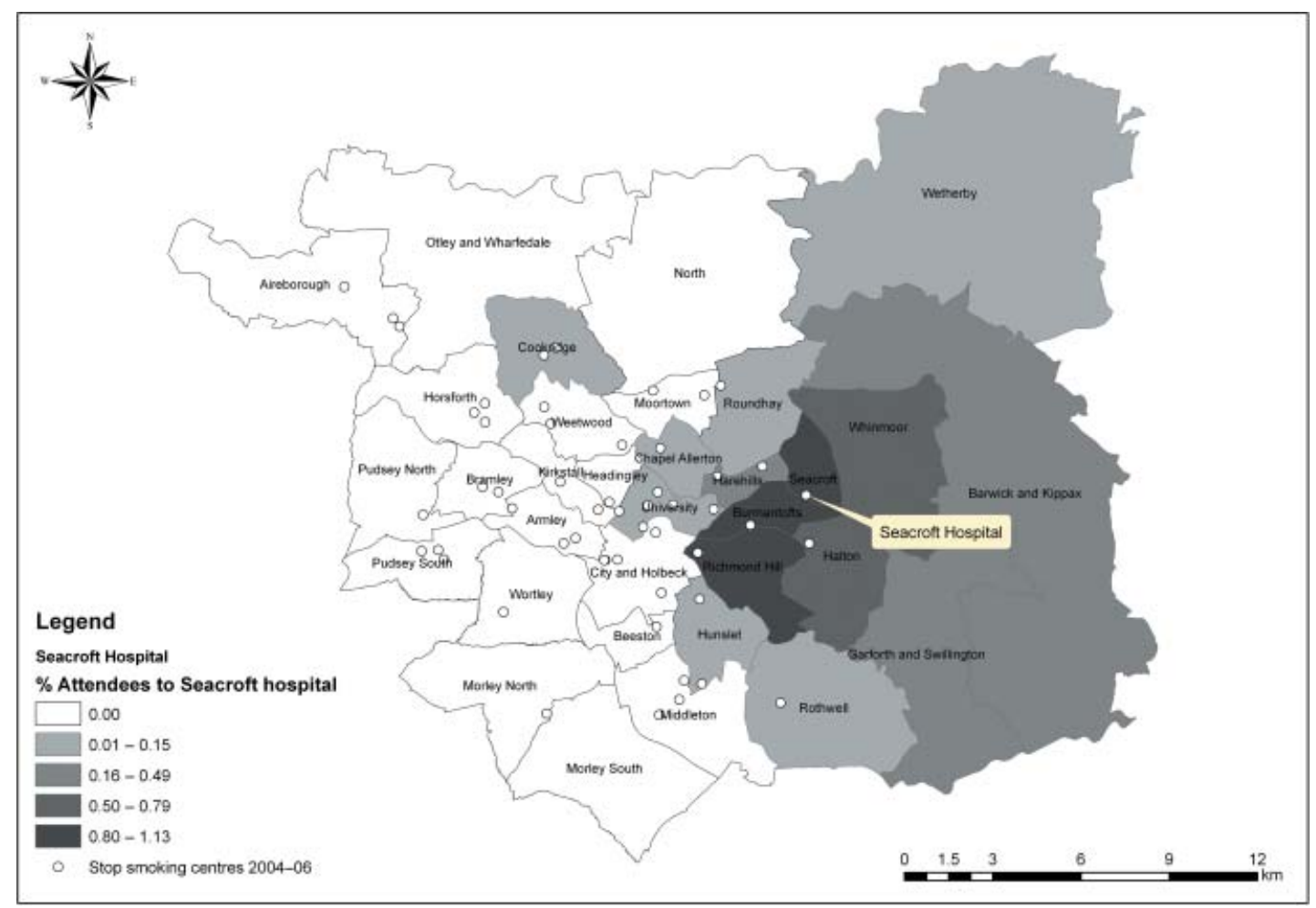

Figure 6 Catchment area for the attendees at Seacroft Hospital

The method to be adopted here is the p-median problem as the focus is to minimise total distance travelled (the further away the service, generally the lower the uptake), emphasising the importance of geography or distance-decay effects. In reality, when people cannot access certain facilities, utilisation is normally lower. Studies have highlighted that distance between home/work and medical centres influences the number of health visits and people sometimes do not go to primary healthcare centres even though they actually need to visit them (Carr-Hill et al. 1997; Haynes and Bentham 1982; Nemet and Bailey 2000). Demographic and socio-economic factors strongly influence the access to a health service: for instance, people with low incomes and no cars are more dependent on public transport, which is often poor away from key arterial routes. This is especially crucial for young people with low or no income or for the elderly, more immobile population. Therefore, disadvantaged groups often make less frequent visits to facility locations.

To solve the $\mathrm{p}$-median problem the following data are required:
- Number of demand sites (number of estimated smokers in each OA).

- Number of possible supply sites (number of stop smoking centres).

- Distance, time or cost of travel from each demand site to each potential supply site.

- Number of new facilities to open.

The p-median problem can be written as follows (Cromley and McLafferty 2002):

Objective function:

Minimise $Z=\sum_{i \in l} \sum_{j \in J} a_{i} d_{i j} x_{i j}$

Subject to the constraints:

An individual demand site must be assigned to a facility $x_{i j} \leq x_{i j}$ for all (i, j)

Demand must be assigned to an open facility $\sum_{j \in J} X_{i j}=1$ for all i

Exactly $p$ facilities must be located $\sum_{j \in J} X_{j j}=p$ for all j

All demand from an individual demand site is assigned to only one facility $x_{i j}=(0,1)$ for all $(i, j)$ 
Table 2 Location-allocation results for each day of a typical week (figures are rounded)

\begin{tabular}{|c|c|c|c|}
\hline & $\begin{array}{l}\text { Longest distance one } \\
\text { has to travel to the } \\
\text { nearest centre }(\mathrm{km})\end{array}$ & $\begin{array}{l}\text { Average distance } \\
(\mathrm{km})\end{array}$ & $\begin{array}{c}\% \text { of smokers who } \\
\text { need to travel further } \\
\text { than } 5 \mathrm{~km}\end{array}$ \\
\hline \multicolumn{4}{|l|}{ Monday } \\
\hline 11 existing centres & 7.8 & 2.4 & 23.6 \\
\hline 11 'optimal' centres & 1.6 & 3.0 & 3.9 \\
\hline \multicolumn{4}{|l|}{ Tuesday } \\
\hline 19 existing centres & 11.0 & 2.1 & 13.8 \\
\hline 19 'optimal' centres & 10.0 & 2.6 & 0.4 \\
\hline \multicolumn{4}{|l|}{ Wednesday } \\
\hline 15 existing centres & 5.5 & 2.3 & 27.8 \\
\hline 15 'optimal' centres & 2.5 & 2.9 & 2.6 \\
\hline \multicolumn{4}{|l|}{ Thursday } \\
\hline 15 existing centres & 11.0 & 2.1 & 23.0 \\
\hline 15 'optimal' centres & 2.5 & 2.9 & 2.6 \\
\hline \multicolumn{4}{|l|}{ Friday } \\
\hline 9 existing centres & 11.0 & 2.5 & 39.3 \\
\hline 9 'optimal' centres & 10.5 & 3.1 & 9.4 \\
\hline \multicolumn{4}{|l|}{ Saturday } \\
\hline 2 existing centres & 10.6 & 2.9 & 76.1 \\
\hline 2 'optimal' centres & 1.9 & 3.4 & 53.0 \\
\hline
\end{tabular}

where:

$\mathrm{Z}$ is the objective function (see equation 1)

$\mathrm{I}$ is the set of demand areas and the subscript $\mathrm{i}$ is an index denoting a particular demand area

$\mathrm{J}$ is the set of candidate facility sites and the subscript $j$ is an index denoting a particular facility site $a_{i}$ is the number of people at demand site $i$

$\mathrm{d}_{\mathrm{ij}}$ is the distance or time (travel cost) separating place $i$ from candidate facility site $j$

$x_{i j}$ is 1 if demand at place $i$ is assigned to a facility opened at site $j$ or 0 if demand at place $i$ is not assigned to that site

$p$ is the number of facilities to be located.

For the location-allocation model there are various ways to calculate distance. The easiest and computationally fastest is the Euclidean distance, which calculates the route from one point to another as a straight line, whereas road networks reflect real travel patterns more closely. Hence a road network was implemented where OS Meridian 2 data were downloaded from Digimap with the scale 1:50 000 (http://digimap2.edina.ac.uk/downloader/Downloader? tab=0; accessed 16 January 2007) and a road network was built within a GIS. Church and Sorensen (1996) point out that there are two basic approaches to solve the p-median model: optimal and heuristic.
Optimal techniques would take a high amount of computation time for larger datasets and hence mostly heuristic processes are used to obtain reasonable results. Heuristics are algorithms that work faster when working with large datasets by providing a result close to the 'optimal' result but do not guarantee that the best result will be found. The first heuristic for the p-median problem was developed by Teitz and Bart and other heuristics followed, such as genetic algorithms, simulated annealing, TABU search, GRASP, hybrids and GRIA (Global-Regional Interchange Approach). The two heuristics Teitz and Bart and GRIA were embedded into ESRI's network module developed for Arclnfo7.0 (for more detail see Church and Sorensen 1996) and for this work GRIA was chosen (which is the predefined command).

In October 2006, 51 stop smoking services were run between Monday and Saturday at different times of the day. The following analysis is based on such a typical week. Table 2 shows the overall results of comparing the results from the location-allocation model (optimal sites) with the actual sites chosen by the healthcare planners on each day of the week. The summary indicator chosen is the number of smokers that have to travel more than $5 \mathrm{~km}$ to reach a service location. The demand population in the model is the number of smokers estimated through 


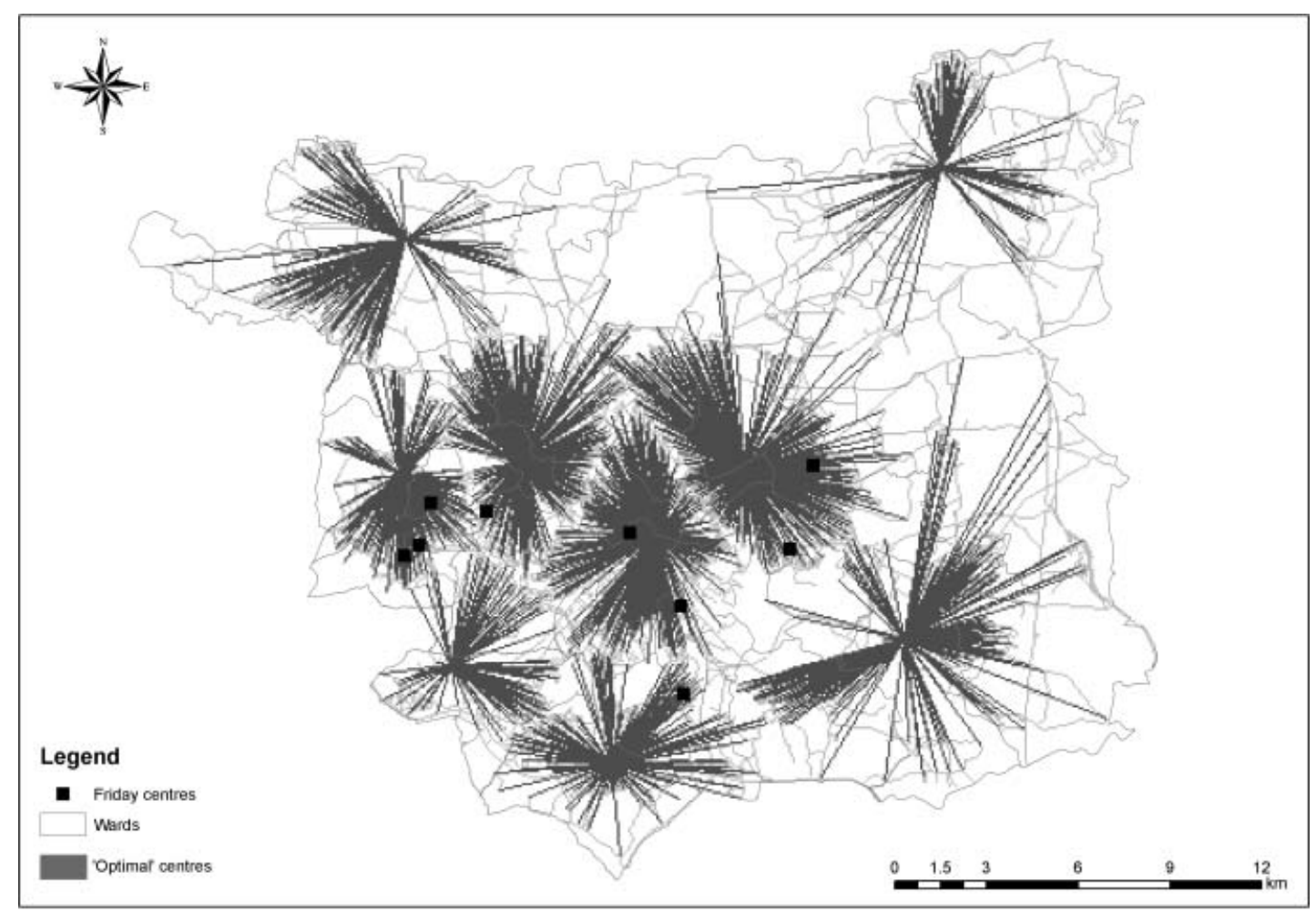

Figure 7 Nine actual centres (black squares) compared with nine 'optimal' centres (centre of spider plot) on a typical Friday

the microsimulation model for Leeds OAs. ESRI's Arclnfo Workstation is used to construct the location-allocation model. The results of scenarios for each day are shown in Table 2 .

It can be seen that the 'optimal' locations reduce the travel distance for smokers on all days. The best reduction can be seen on Friday, where 30 per cent more smokers could be reached. Figure 7 shows the results of the scenario mapped for Friday using Arclnfo. The results are shown as spider maps, where the centre of the spider is the 'optimal' location for a stop smoking service and the legs of the spider show the area it covers. The black squares show the nine current stop smoking centres, whereas the centre point of the grey spiders show the 'optimal' locations and the grey lines indicate the area that is covered by a particular centre. The light grey lines beneath the spider plots show the road network and dark grey boundaries are the ward boundaries (for better orientation). It can be seen that currently the centres available every Friday are quite clustered in the western part of Leeds and no sessions are available in the north and east at all on that day. Here the model locates one centre in each of the north-east, north-west, east and south, and two in central Leeds where there are no centres. Only three of the current centres are near optimally modelled locations. The results from the nine existing Friday centres show that 39 per cent of the smoking population would need to travel more than $5 \mathrm{~km}$ to access their nearest stop smoking service, whereas the outcome from the location-allocation model reduces this to 9 per cent.

Table 2 shows that the 19 centres open on a Tuesday in comparison to the weekend, when no sessions are running on a Sunday and only two on a Saturday. Therefore it would be beneficial to move some sessions to the weekend. These results should be a starting point for healthcare planners to redistribute the centres in a more efficient way, although more criteria need to be taken into account, such as varied opening times of services, and people's willingness to give up. Discussions with Leeds PCT are now on-going in relation to future service provision. 


\section{Discussion and conclusion}

The results above show the importance of estimating smoking prevalence at small areas to help tackle health inequalities and to locate services more efficiently and effectively. A preliminary analysis of the smoking prevalence for different demographic and socio-economic variables was shown at the start of the paper. This analysis showed that there is a need to combine these variables (as each variable on its own showed different spatial patterns) and for this purpose microsimulation is a useful and powerful methodology.

Mapping the market penetration of stop smoking centres is useful to identify areas with relatively high rates of attendance and it helps to identify elements of performance relating to target numbers. Areas with low attendance could be the result of individuals facing problems accessing the service. More in-depth analysis about the reasons for non-attendance is suggested.

Finding the best locations for stop smoking services is crucial to meet the national targets in relation to lower smoking rates. Location-allocation models are a useful tool as numerous scenarios can be created. Here, the present versus the optimal locations on a specific day were modelled and average distance travelled was calculated and expressed as the number of smokers that have to travel further than $5 \mathrm{~km}$ to reach stop smoking services. Clearly, if health planners felt that in the future $5 \mathrm{~km}$ was too far to travel, then this could be reduced and the accessibility scores re-calculated.

One has to keep in mind that the small-area smoking rates used in this paper are only estimates and that it is not possible to construct the real smoking population without extensive data collection. Only the people aged 16-74 were modelled, which hides a certain proportion of smokers. Further, the PCT has to face certain constraints, including focusing only on particular deprived areas or they do not get any premises for their services. This makes it difficult to distribute centres more equally or probably efficiently. The location-allocation analysis here is based on people travelling from their home to their nearest centre, which means people travelling from their workplace to a centre are not captured.

Future work will involve policymakers in the development of new scenarios. For example, there is interest in targeting specific population groups such as women aged 30-44 (as the statistics show they are the group most likely to quit) or to target different ethnic groups (such as Bangladeshi men, as they have a very high smoking prevalence). Also the time of the day could be modelled to see the potential impacts on changing opening times, and the travel patterns of those that rely on public transport could be more explicitly addressed in the network analysis part of the location-allocation models. Finally, other 'what if' modelling scenarios could give supporting information for policymakers and healthcare planners in the future. These might include forecasting smoking patterns based on previous trends and updating the population base through modelling births, deaths and migrations. Further interest lies in the impacts of the smoking ban in public places which came into force in July 2007 . The impacts in Leeds could be modelled by using data/trends seen in other areas which have witnessed such a ban earlier than England (such as Ireland and Scotland). Additional 'what if' policy scenarios can include the impacts of media campaigns or tax increases on the smoking population in England.

The combination of microsimulation and locationallocation models in this paper showed the power of the analyses to support decisionmakers and it is the first time that such analyses have been applied. The findings of this research will hopefully lead to a new approach to targeting smokers in Leeds and allow centre locations to be found that should help to decrease inequalities of access for different population groups and in turn reduce health inequalities.

\section{Acknowledgements}

We would like to thank the White Rose Consortium for funding this research. Thanks also to the Leeds PCT for its collaboration and for providing datasets. The 2001 Census Output Area Boundaries and Ward Boundaries are Crown copyright 2003 where Crown copyright material is reproduced with the permission of the Controller of HMSO. The data to build a road network are Crown Copyright/database 2007 and an Ordnance Survey/EDINA supplied service.

\section{References}

Ballas D, Rossiter D, Thomas B, Clarke G and Dorling D 2005 Geography matters: simulating the local impacts of national social policies Joseph York, Rowntree Foundation, UK

Barbeau E M, Wolin K Y, Naumova E N and Balbach E 2005 Tobacco advertising in communities: associations with race and class Preventive Medicine 40 16-22

Birkin M and Clarke G 1995 Using microsimulation methods to synthesize census data in Openshaw $\mathbf{S}$ ed Census users' handbook Pearson Professional Limited, Cambridge 363-87 
Blackburn C, Spencer N, Bonas S, Coe C, Dolan A and Moy R 2003 Effect of strategies to reduce exposure of infants to environmental tobacco smoke in the home: cross sectional survey British Medical Journal 327 257-61

Carr-Hill R, Place M and Posnett J 1997 Access and utilisation of health care services in Ferguson B, Posnett J and Sheldon D A eds Concentration and choice in healthcare Financial Times Healthcare, London 37-49

Church R L and ReVelle C S 1974 The maximal covering location problem Papers of the Regional Science Association 32 101-18

Church R L and Sorensen P 1996 Integrating normative location models into GIS: problems and prospects with the p-median problem in Longley $\mathbf{P}$ and Batty $\mathbf{M}$ eds Spatial analysis: modelling in a GIS environment Pearson Professional Ltd,

Clarke G 1996 Microsimulation for urban and regional policy analysis Pion Limited, London

Cromley E K and McLafferty S L 2002 GIS and public health The Guilford Press, London

Datta G D, Subramanian S V, Colditz G A, Kawachi I, Palmer J R and Rosenberg L 2006 Individual, neighborhood, and statelevel predictors of smoking among US black women: a multilevel analysis Social Science \& Medicine 63 1034-44

Department of Health 1992 Effect of tobacco advertising on tobacco consumption: a discussion document reviewing the evidence Economics \& Operational Research Division,

Department of Health 1998 Smoking kills: a white paper on tobacco Stationery Office, London

Department of Health 2004 Choosing health: making healthy choices easier Stationery Office, London

Department of Health 2006 Our health, our care, our say: a new direction for community services Stationery Office, London

Doll R and Hill A B 1950 Smoking and carcinoma of the lung British Medical Journal 30 739-48

Edwards R 2004 The problem of tobacco smoking British Medical Journal 328 217-19

Elliott M 2000 The stress process in neighborhood context Health \& Place 6 287-99

Fichtenberg C M and Glantz S A 2002 Effect of smoke-free workplaces on smoking behaviour: systematic review British Medical Journal 325 188-95

Goddard E 2005 General Household Survey 2005: smoking and drinking among adults, 2005 Office for National Statistics, London

Goddard E 2006 General Household Survey 2006: smoking and drinking among adults, 2006 Office for National Statistics, Newport

Gordon D, Shaw M, Dorling D and Smith G D 1999 Inequalities in health: the evidence The Policy Press, Bristol

Hackshaw A K, Law M R and Wald N J 1997 The accumulated evidence on lung cancer and environmental tobacco smoke British Medical Journal 315 980-8

Hakimi S L 1964 Optimum locations of switching centres and the absolute centres and medians of a graph Operations Research 12 450-9 Cambridge 167-84 Department of Health, London

Haynes R M and Bentham C G 1982 The effects of accessibility on general practitioner consultations, out-patient attendances and in-patient admissions in Norfolk, England Social Science \& Medicine 16 561-9

He J, Vupputuri S, Allen K, Prerost M R, Hughes J and Whelton P K 1999 Passive smoking and the risk of coronary heart disease - a meta-analysis of epidemiologic studies New England Journal of Medicine 340 920-6

Hodgson M J 1988 An hierarchical location-allocation model for primary health care delivery in a developing area Social Science \& Medicine 26 153-61

Luke D, Esmundo E and Bloom Y 2000 Smoke signs: patterns of tobacco billboard advertising in a metropolitan region Tob Control 9 16-23

Møller-Jensen L and Kofie R Y 2001 Exploiting available data sources: location/allocation modeling for health service planning in rural Ghana Danish Journal of Geography 101 145-53

Nemet G F and Bailey A J 2000 Distance and health care utilization among the rural elderly Social Science \& Medicine 50 1197-208

Orcutt G H, Merz J and Quinke H 1986 Microanalytic simulation models to support social and financial policy Elsevier Science Publishers B V, Amsterdam

Pearce J, Boyle P and Flowerdew R 2003 Predicting smoking behaviour in census output areas across Scotland Health and Place 9 139-49

Peto R 1994 Smoking and death: the past 40 years and the next 40 British Medical Journal 309 937-9

Ross N A, Rosenberg M and Pross D 1994 Siting a women's health facility: a location-allocation study of breast cancer screening services in Eastern Ontario The Canadian Geographer 38 150-61

Sargent J D and Dalton M 2001 Does parental disapproval of smoking prevent adolescents from becoming established smokers? Pediatrics 108 1256-62

Smith D M, Clarke $\mathbf{G}$ and Harland $\mathbf{K}$ in press Improving the synthetic data generation process in spatial microsimulation models Environment and Planning $A$

Stanton H J, Martin J and Henningfield J 2005 The impact of smoking on the family Current Paediatrics 15 590-8

The Healthy Leeds Partnership 2006 Leeds tobacco control strategy 2006 to 2010 Leeds Initiative, Leeds

Toregas C, Swain R W, ReVelle C S and Bergman L 1971 The location of emergency service facilities Operations Research 19 1363-73

Twigg L, Moon G and Jones K 2000 Predicting small-area health-related behaviour: a comparison of smoking and drinking indicators Social Science \& Medicine 501109 20

Twigg L, Moon G and Walker S 2004 The smoking epidemic in England Health Development Agency, London

Vaish A K, Sathe N and Folsom R E 2004 Small area estimates of diabetes and smoking prevalence in North Carolina counties: 1996-2002 behavioral risk factor surveillance system Proceedings of the American Statistical Association

Area Vol. 40 No. 3, pp. 341-353, 2008

ISSN 0004-0894 (C) The Authors.

Journal compilation (C) Royal Geographical Society (with The Institute of British Geographers) 2008 